\title{
P3 amplitude reductions are associated with shared variance between internalizing and externalizing psychopathology
}

\author{
Edward M. Bernat ${ }^{1}$ ｜ Jessica S. Ellis ${ }^{1}$ iD | Matthew D. Bachman ${ }^{2}$ | Brian M. Hicks ${ }^{3}$
}

${ }^{1}$ Department of Psychology, University of Maryland, College Park, MD, USA

${ }^{2}$ Center for Cognitive Neuroscience, Duke University, Durham, NC, USA

${ }^{3}$ Department of Psychiatry, University of Michigan, Ann Arbor, MI, USA

\section{Correspondence}

Edward M. Bernat and Jessica S. Ellis, Department of Psychology, University of Maryland, 0126 Biology/Psychology Building, College Park, MD 20742, USA. Email: ebernat@umd.edu (E. M. B.) and jellis18@umd.edu (J.S. E.)

Funding information

National Institutes of Health, Grant/Award Number: K08MH080239

\begin{abstract}
P3 amplitude reductions, commonly elicited in oddball paradigms, have been associated with both internalizing (e.g., depression and anxiety) and externalizing problems (e.g., substance use, aggression, and impulsivity). Recent factor analytic models have focused on the shared variance between internalizing and externalizing problems as a potentially important separable psychopathology construct (a general psychopathology factor, or $p$-factor). To assess neurophysiological markers of this shared variance, we examined P3 amplitude to target and novel stimuli in an undergraduate sample with a range of internalizing and externalizing problems. Participants $(N=125)$ completed a rotated heads visual oddball paradigm, with IAPS pictures serving as infrequent novel stimuli. Results replicated P3 amplitude reduction relative to both target and novel stimuli separately for internalizing and externalizing problems, and found that the shared variance across internalizing and externalizing was significantly related to lower P3 amplitude to novels, targets, and a factor score of target and novel P3 measures. The present results are consistent with the interpretation that a general or shared problem behavior factor accounts for much of the associations between reduced $\mathrm{P} 3$ amplitude and internalizing and externalizing problems.
\end{abstract}

\section{K E Y W O R D S}

ERPs, externalizing, internalizing, oddball task, P300, p-factor

\section{INTRODUCTION}

The $\mathrm{P} 3$ or $\mathrm{P} 300$ is one of the most widely studied event-related potentials (ERPs) in both basic and clinical science studies. As a measure of attention allocation, basic information processing, and working memory (Polich, 2007), examining the P3 may provide some insight into neurophysiological markers underlying cognitive deficits related to psychopathology. Across a number of studies, individuals with a broad range of psychological and neurobiological disorders have shown decreased P3 amplitude in comparison to control groups (Dierks, Frölich, Ihl, \& Maurer, 1994; Hansenne, Pitchot, Papart, \& Ansseau, 1998; Knight, Scabini, Woods, \& Clayworth, 1989; Pooviboonsuk, Dalton, Curran, \& Lader, 1996; Rimpel et al., 1995). In addition to P3 amplitude reduction occurring within diagnostic categories, there is also some evidence indicating P3 amplitude reductions may be markers of shared or nonspecific processes that contribute to multiple disorders (Patrick et al., 2006), and that this shared variance indexes genetic risk for these disorders (e.g., >80\%; Hicks et al., 2007; Kendler, Prescott, Myers, $\&$ Neale, 2003; Krueger et al., 2002). Based on evidence 
pointing to a similar P3 effect across disorders, the current study aimed to further examine whether P3 modulation reflects a shared index across psychopathology constructs.

\section{1 | Two-dimensional model of psychopathology}

A widely accepted theoretical framework for classifying psychopathology constructs is a two-dimensional model which classifies most disorders into either externalizing (aggression, delinquency, and impulsivity) or internalizing conditions (anxiety and depression; Krueger, 1999; Krueger \& Markon, 2006). Structural models of psychopathology support the theory of a shared process by suggesting that externalizing and internalizing disorders share significant variance, reflecting a common process that is an appropriate target of study (Caspi et al., 2014). Despite the widespread observance of reduced P3, and the emerging interest in shared processes across psychopathology constructs, there have been few studies to examine P3 as a marker of these shared processes.

\subsection{1 | Externalizing}

P3 amplitude reductions have been associated with a wide range of externalizing behaviors including alcoholism, substance abuse, conduct disorder, and antisocial personality disorder (Bauer \& Hesselbrock, 1999; Iacono, Malone, \& McGue, 2003; Patrick et al., 2006; Polich, Pollock, \& Bloom, 1994; Porjesz, Begleiter, \& Garozzo, 1980), such that greater severity within each domain has been associated with smaller P3 amplitudes. However, P3 reduction may not be a unique effect in each disorder. Previous research found that a single factor representing the shared variance across a range of externalizing behaviors significantly predicted P3 amplitude reduction (Patrick et al., 2006), indicating that reduced P3 may not be specific to certain populations, but instead could represent a marker of a broader spectrum of psychopathology (Begleiter \& Porjesz, 1999). Another study which used twin participants in a large-scale longitudinal design found the relationship between P3 amplitude and externalizing was attributable to shared genetic influences (Hicks et al., 2007). Additional epidemiological twin studies also lend support for a broad and highly heritable externalizing factor (Kendler et al., 2003; Krueger et al., 2002). Based on the established connection between genes and risk for development of externalizing behaviors, emerging research suggests neurophysiological markers such as P3 amplitude are an important topic of study and could represent a biomarker of transdiagnostic psychopathology constructs (Hicks et al., 2007; Patrick et al., 2006).

\subsection{2 | Internalizing}

\section{Depression}

P3 amplitude reduction has also been associated with internalizing problems. The strongest associations have been with depression, where several studies have found greater reductions in P3 for depressed populations compared to control groups (Baribeau-Braun \& Lesevre, 1983; Blackwood et al., 1987; Deldin, Keller, Gergen, \& Miller, 2001; Diner, Holcomb, \& Dykman, 1985; Enoch, White, Harris, Rohrbaugh, \& Goldman, 2001; Gangadhar, Ancy, Janakiramaiah, \& Umapathy, 1993; Nan et al., 2018; Pfefferbaum, Wenegrat, Ford, Roth, \& Kopell, 1984; Röschke \& Wagner, 2003; Singh, Shukla, Dalal, Sinha, \& Trivedi, 2000; Thier, Axman, \& Giedke, 1986). Additional avenues of research have explored whether the particular type of depression has an effect on P3. These studies found amplitude reductions across subtypes, including reduced P3 for melancholic (Gangadhar et al., 1993), suicidal (Hansenne, Pitchot, Moreno, Zaldua, \& Ansseau, 1996), and psychotic (Karaaslan, Gonul, Oguz, Erdinc, \& Esel, 2003) features of depression. Some research on risk for depression suggests even healthy subjects with a family history of the disorder show reduced P3 amplitude (Houston, Bauer, \& Hesselbrock, 2003). These findings provide some evidence that P3 amplitude reductions may operate similarly across facets of depression, as well as in samples at risk for depression.

\section{Anxiety}

In contrast to mostly consistent findings in depression and externalizing, studies of individuals with anxiety have produced mixed P3 results, including some showing enhanced amplitudes or longer latencies (Kimble, Kaloupek, Kaufman, \& Deldin, 2000; Morault, Bourgeois, Laville, Bensch, \& Paty, 1997), while others show maximum amplitude reductions in comorbid samples with anxiety (Bauer, Costa, \& Hesselbrock, 2001; Enoch et al., 2001). A recent study examined P3 amplitude in treatment resistant depression and generalized anxiety disorder patients and found significant P3 reduction in both patient groups compared to the healthy control group (Xu et al., 2014). Thus, it is unclear if anxiety alone is robustly associated with P3 amplitude reductions, or if comorbidity with depression (e.g., internalizing) is central to observed effects.

\section{2 $\quad$ P3 Reduction as a shared process across psychopathology constructs}

Despite research showing reduced P3 for externalizing and depression, and some evidence for anxiety, few studies have examined whether P3 amplitude reduction represents a shared or independent process across these behaviors. 
Although factor analytic models provide support for distinct externalizing and internalizing factors, they do not represent completely separate and unique constructs. In fact, the two factors show moderate to high correlations (e.g., $r=.51$; Krueger, 1999) and their shared variance is an important topic of study (Caspi et al., 2014; Lahey, Krueger, Rathouz, Waldman, \& Zald, 2017). Given the correlation between these two dimensions, one might expect P3 amplitude reduction to be partially explained by the shared variance across psychopathology constructs. However, of those studies assessing shared variance in predicting $\mathrm{P} 3$, they have been limited to a single domain of behaviors (e.g., externalizing or comorbid anxiety and depression). For example, Patrick and colleagues (2006) focused exclusively on the externalizing dimension and found that P3 amplitude reduction across $D S M-I I I-R$ defined substance use disorders, conduct disorder, and antisocial personality disorder was best explained by their shared variance. A follow-up study showed similar P3 amplitude reductions related to increases in externalizing proneness (Nelson, Patrick, \& Bernat, 2011) using a self-report measure of externalizing problems (Krueger, Markon, Patrick, Benning, \& Kramer, 2007). Although these studies provided important contributions to the literature by suggesting that reduced P3 amplitude may be best reflected by a broader spectrum of behaviors described by the shared variance across externalizing problems, it did not examine whether this shared process extends to internalizing behaviors such as depression and anxiety.

\section{3 $\quad$ P3 to target and novel stimuli}

Another understudied area in the literature is whether P3 amplitude reduction is specific to task conditions or is a broad effect across task conditions. The P3 has been used in a number of studies as a measure of cognitive resource allocation and the activation of cognitive schemas to process task information (Johnson, 1993). Often elicited 250 to $400 \mathrm{~ms}$ after stimulus presentation during a simple two-stimulus target discrimination task (e.g., oddball paradigm), the P3 consists of a positive wave typically recorded over the central-parietal area (Polich \& Herbst, 2000; Polich \& Kok, 1995). While P3 has been attributed to processing of both task relevant (e.g., target) and task-irrelevant (e.g., infrequent nontarget and novel) stimuli (Picton, 1992; Sutton, Braren, Zubin, \& John, 1965; Yamaguchi \& Knight, 1991), these two processes represent subcomponents of P3 with distinct neural generators and cognitive operations. The most widely studied subcomponent in this paradigm is the "P3b" elicited by target stimuli with a parietal scalp distribution. The second subcomponent is known as the "P3a", and occurs slightly earlier in latency with a broadly frontocentral distribution (Polich, 2012). The "P3a" is elicited following infrequent, nontarget stimuli, such as a non-repeating novel stimulus (Polich \& Comerchero, 2003; Polich \& Criado, 2006; Simons, Graham, Miles, \& Chen, 2001). Crucially, the elicitation of the P3a is dependent upon stimulus context, as it becomes more pronounced when discrimination between targets and standards becomes more difficult and the infrequent nontarget or novel stimulus itself is distinct (Comerchero \& Polich, 1998, 1999; Demiralp, Ademoglu, Comerchero, \& Polich, 2001; Hagen, Gatherwright, Lopez, \& Polich, 2006; Katayama \& Polich, 1998; Polich \& Comerchero, 2003).

In addition to having different topographical distributions, it has been suggested that $\mathrm{P} 3 \mathrm{a}$ and $\mathrm{P} 3 \mathrm{~b}$ represent separate cognitive processes, with the former reflecting frontal attention orienting and the latter representing attention and context updating (Polich, 2007). While the majority of work on P3 amplitude reduction in relation to psychopathology has focused on P3b during target processing, these earlier versions of oddball P3 studies were limited to two categories of standard/frequent nontarget and target stimuli. However, more recent use of the oddball task incorporates a three-stimulus version with strong evidence suggesting that the third category representing infrequent novel stimuli is compelling for contributing to our understanding P3 reductions related to clinical problems (Polich, 2004), including depression (Bruder, Kayser, \& Tenke, 2012) and substance use (Holguín, Porjesz, Chorlian, Polich, \& Begleiter, 1999). These studies suggest novelty-P3 may provide useful information about attention processes during infrequent events that may be disrupted in individuals with psychological abnormalities. In this way, assessing P3 modulation to both target and novel stimuli is important for understanding convergent or divergent cognitive processes affected by individual differences.

\section{4 | Current study}

The aim of the present study is to assess whether self-report measures of externalizing, depression, and anxiety demonstrate P3 amplitude reduction to both target and novel stimuli with the specific goal of determining whether this amplitude change reflects a shared index across psychopathology constructs. Positive findings would support the hypothesis that the shared variance across externalizing and internalizing constructs is a fruitful target of study and that P3 amplitude may be an appropriate index of that shared variance.

\section{2 | METHOD}

\section{1 | Participants}

A total of 148 undergraduate students from a large southeastern university and volunteer community members 
participated in this study. Seven participants were excluded due to problems with data collection, nine were excluded due to an excessive number of EEG artifacts ( $>33 \%$ of trials rejected using methods described in Data Preprocessing), and seven were removed from analysis due to lack of complete questionnaire data. This left a total of 125 participants for analysis (70 females, 55 males; $M$ age $=20.01$ years, $S D=3.77$ years). All participants were 18 years of age or older, and were screened for neurological conditions, visual impairments, and traumatic brain injuries. Participants were $84.8 \%$ white, $6.4 \%$ African American, 3.2\% Asian Indian, $2.4 \%$ Asian, and $.8 \%$ other $(84.8 \%$ non-Hispanic, $11.2 \%$ Hispanic, and $5 \%$ did not report or missing). Due to the difficulty of recruiting undergraduate students with high levels of externalizing behaviors, part of the selection process included sampling participants from the highest and lowest quartiles in the distribution of scores on the Externalizing Spectrum Inventory (ESI; Krueger et al., 2007). Participants selected from this sampling method were chosen from a larger sample of undergraduate and community members $(N=2,386)$ who completed the ESI as part of a prescreening instrument. Based on the distribution of within-gender normalized scores, individuals from within the highest and lowest externalizing quartiles were over-sampled for participation in order to ensure a representative sample across the full range of externalizing severity. Of the 125 participants in the final sample, $31(24.8 \%$, range $=.21-57, M=.34, S D=.096)$ scored in the highest externalizing group and $40(32.0 \%$, range $=$ $.01-10, M=.05, S D=.028$ ) scored in the lowest externalizing group, while the remaining $54(43.2 \%$, range $=$ $.06-27, M=.1408, S D=.055)$ participants fell within the middle $50 \%$ of scores on the ESI. Participants provided informed consent before starting the study and were given the option of monetary compensation or course credit in return for time spent during participation.

\subsection{Self-report questionnaire data}

All participants completed self-report questionnaires representing continuous measures of externalizing, depression, and anxiety behaviors. Externalizing behaviors were assessed using the ESI-100, a 100 item self-report instrument composed of the items with strongest loadings on the general factor from the 415 items of the original ESI form (Krueger et al., 2007), which we have used previously to assess the relationship between P3 amplitude and externalizing problems (Bernat, Nelson, Steele, Gehring, \& Patrick, 2011; Hall, Bernat, \& Patrick, 2007; Nelson et al., 2011). Participants responded to questions using a 4-point Likert scale consisting of "True," "Mostly true," "Mostly false," and "False." Externalizing scores were calculated as a prorated proportion of severity ranging from 0 to 1 where 1 indicates scoring at the highest severity level possible on all items, and 0 indicates no externalizing behaviors across any of the 100 items. Depression behaviors were assessed using the Zung Self-Rating Depression Scale (Zung, 1965) and calculated as a sum of all 20-items on a 4-point Likert scale. Behaviors representing anxiety were measured by the 20-item Spielberger State Trait Anxiety Inventory-Trait and were calculated similarly to the Zung depression scale as a sum of all 20 items (STAI-T; Spielberger, Dorsuch, \& Lushene, 1970).

\section{3 | Procedure}

Data collection were conducted in a dimly lit, sound-attenuated room. Experimental stimuli were presented on a 21-inch Dell high-definition CRT color monitor, centrally placed at a viewing distance of $100 \mathrm{~cm}$. E-Prime version 1.1 and version 2.0 were used to present the computer task. A PST Serial Response Box (Psychology Software Tools, Inc.) was used to present stimuli, as well as collect responses to the task.

Participants performed a three-stimulus variant of the "rotated-heads" visual oddball task (Begleiter, Porjesz, Bihari, \& Kissin, 1984). The task consisted of 240 trials, each of which were presented on the screen for $100 \mathrm{~ms}$ in eight blocks. The task included 168 trials (70\%) representing a frequent oval stimulus, to which participants were instructed to not respond. Another 36 trials (15\%) consisted of an oval representing a head, with one ear and nose, representing target stimuli. Participants were instructed to respond to the target stimuli with one of two button presses, according to the whether the ear was located on the left or right side of the head. On half of these trials, the head was rotated $180^{\circ}$, representing a more difficult discrimination for participants. The last type of stimuli category consisted of 36 trials (15\%) representing novel stimuli, which consisted of 12 highly pleasant (IAPS image numbers: 1,710, $2,040,2,150,2,340,4,210^{\star}, 4,572^{\circ}, 4,659,4,660,4,687$, $5,621,8,030,8,080,8,370),{ }^{1} 12$ highly unpleasant $(1,525$, $2,811,3,000,3,010,3,060,3,080,6,230,6,250,6,260$, $6,300,6,370,6,830)$, and 12 neutral images $(2,038,2,190$, 2,480, 2,840, 7,000, 7,004, 7,010, 7,020, 7,041, 7,175, 7,185, 7,187), taken from the International Affective Picture Set (IAPS; Center for the Study of Emotion and Attention, 1999). These pictures appeared randomly in place of target or frequent stimuli. Between each trial was an inter-trial interval (ITI), whose duration varied between 1 to 2 s. During this ITI, participants were instructed to fixate on a small dot on the center of the screen. The task

\footnotetext{
${ }^{1}$ o Shown only to male participants. @Shown only to female participants.
} 
took 18 min to complete. Before the task began, participants were given a short practice consisting of 12 frequent and eight target stimuli, but EEG data for this practice were not collected for data analysis.

\subsection{Psychophysiological data acquisition}

Data were recorded using a Neuroscan 128-channel QuikCap (sintered $\mathrm{Ag}-\mathrm{Ag} / \mathrm{Cl}$; non-standard layout) as well as a 128-channel Synamps RT amplifier (Neuroscan, Inc.). Ten electrodes around the ears were removed from analysis due to inadequate connection to the scalp for a majority of participants, leaving a total of 113 EEG channels. Horizontal electrooculogram activity was recorded from electrodes placed on the outer canthus of both eyes, while vertical electrooculogram activity was recorded from electrodes placed above and below the left eye. Impedances were kept below $10 \mathrm{k} \Omega$. EEG signals were vertex referenced during recording, and referenced to averaged mastoid signals offline, collected using an analog 0.05 to $200 \mathrm{~Hz}$ bandpass filter, and digitized at $1,000 \mathrm{~Hz}$ using Neuroscan Acquire (Neuroscan,Inc.).

\section{5 | Data preprocessing}

Epochs of 3,000 ms were then taken from 1,000 ms pre to $2,000 \mathrm{~ms}$ post-stimulus with a $150 \mathrm{~ms}$ pre-stimulus baseline correction and were re-referenced to averaged mastoid sites. Data were corrected for ocular artifacts using a regression based algorithm developed by Semlitsch and colleagues (1986) in the Neuroscan Edit 4.5 software (Neuroscan, Inc.), and downsampled to $128 \mathrm{~Hz}$ using the Matlab resample function (Mathworks, Inc.), which applied an anti-aliasing filter during resampling. Then, two methods of data cleaning were used. In the first method, trials were rejected if activity at $\mathrm{F} 3$ or $\mathrm{F} 4$ exceeded $\pm 100 \mu \mathrm{V}$ in either the pre-stimulus period of $-1,000$ to $-1 \mathrm{~ms}$, or the post-stimulus period of 1 to $2,000 \mathrm{~ms}$. This step was conducted to remove any remaining ocular artifacts after undergoing the automated regression correction. Additionally, within-trial individual electrodes were rejected if activity exceeded $\pm 100 \mu \mathrm{V}$ during the same pre- and post-stimulus time periods. This removed $10.1 \%$ of all trials from analysis. The second method of data cleaning included visual analysis of the averaged waveforms, which indicated that 54 electrodes out of 14,125 total were disconnected during recording and were removed from the dataset. After preprocessing, the data were averaged according to stimulus type, either targets ( $M$ trials $=32.47, S D=3.76$ ) or novels ( $M$ trials $=32.46, S D=4.52)$. In order to have a more equivalent number of trials between conditions, target trials included both correct and incorrect responses. We have taken this approach previously, and did not find inclusion of the error trials to change the effects (Bachman \& Bernat, 2018). As noted in the results below, partial correlations, controlling for accuracy, did not change the reported effects.

\section{6 | Time-domain P3 amplitude identification}

Grand average waveforms for target and novel conditions were computed for each of the 113-electrodes across all participants. Using these grand average waveforms, the P3 window was defined as 250 to $500 \mathrm{~ms}$ post-stimulus onset, fitting a window consistent with the $\mathrm{P} 3$ peak across reported frontal, central, parietal, and occipital regions.

\section{$2.7 \quad$ Factor scores}

We used principal axis factoring (PAF) to estimate three latent factor scores in separate analyses (IBM Corp, 2013). First, we estimated scores for an internalizing factor, which was operationalized as the shared variance across the Zung Depression scale and STAI-T scores (the first factor accounted for $88.9 \%$ of the covariance). Next, we included scores on the above internalizing factor and the ESI-100 in a PAF to estimate scores on an internalizing/externalizing (INT/EXT) factor. The first factor of the PAF accounted for $72.0 \%$ of the covariance between the internalizing factor and ESI scores. Finally, we computed a shared P3 factor across target and novel stimuli using an approach we have used previously to assess shared variance across ERP measures (Nelson et al., 2011). The first factor of the PAF that included the target and novel P3 scores accounted for $74.6 \%$ of their covariance.

\section{8 | Data analysis}

A $2 \times 4$ repeated measures General Linear Model with condition (target, novel) by location (frontal, central, parietal, occipital) was conducted to evaluate effects of condition and regional distribution of the effects. Regions were defined by the average of three-electrode clusters over frontal (electrodes $54,60,80)$, central $(51,63,77)$, parietal $(47,66,73)$, and occipital regions $(44,69,70)$. Figure 1 shows topographical locations of these electrodes, color-coded according to their respective region.

Pearson correlations were then calculated between each of the self-report questionnaire total scores (ESI, Zung Depression, STAI-T), P3 amplitude during processing of novel and target stimuli, and the estimated factor scores. Multiple regression models were fit to examine the extent of shared versus unique variance in the internalizing and externalizing scores that accounted for their associations with 


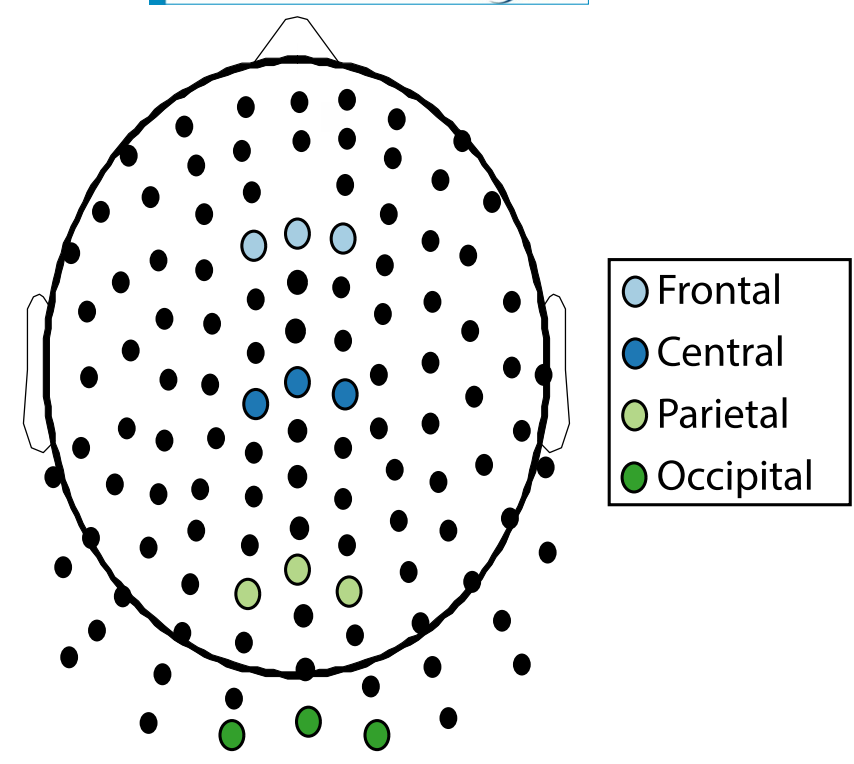

F I G URE 1 A bird's-eye view of the topographical map of electrodes in a 128-channel cap. Electrodes located below the ears are displayed off the cap while maintaining an accurate distance from their respective neighbors. The clusters of electrodes used for assessment of frontal (left to right: electrodes 54, 60, \& 80), 1 regions are indicated by light blue. Central electrodes $(51,63,77)$ are indicated by dark blue. Parietal electrodes $(47,66,73)$ are indicted by light green. Occipital electrodes $(44,69,70)$ are indicated by dark green

P3 amplitudes. P3 amplitude to novel and target stimuli and the target/novel P3 factor score were the dependent variables while externalizing, internalizing, and the INT/EXT factor score were the predictor variables. Secondary analyses tested for effects of other variables including age, gender, and novel picture category on P3 amplitude.

\section{9 | Power: Reproducibility considerations}

We used GPower version 3.1 (Faul, Erdfelder, Erdfelder, Lang, \& Buchner, 2007) to estimate the required effects size at 3 levels of power for $\alpha=.05$ and $N=125$. Results indicated that the current study had $70 \%$ power to detect $r=.193,80 \%$ to detect $r=.220$, and $90 \%$ to detect $r=.258$. In a prior study that used the same externalizing measure and a similar sample (Nelson et al., 2011), we estimated $r$ values of .31 for targets and .32 for novels from the same oddball task, .24 for P3 from a gambling task, and .37 from a flanker task. Therefore, we estimated we would have power over $80 \%$ power to detect the $\mathrm{P} 3$ amplitude reductions related to externalizing. This was similar to our previous work using the externalizing construct, estimated with DSM-III-R diagnoses, based on a larger community sample at age 17 (Patrick et al., 2006), where the $r$ value was .25 . The mean of the effect sizes across these two studies is .298 , for which we would have $96 \%$ power to detect.
For depression and anxiety, while the clinical studies noted earlier have shown significant effects, differences in sampling, design, and results make clear inferences about an expected effect size difficult. However, because we hypothesize that a majority of the $\mathrm{P} 3$ variance related to externalizing is related to shared variance between internalizing and externalizing, we predict the observed effects will be similar in magnitude to our previously published work with externalizing.

\section{3 | RESULTS}

\section{1 | Self-report measures}

Distribution of questionnaire scores ranged from normal to moderate severity levels and are shown in Table 1. Based on the ESI scores, 29 participants were scored as high, 69 as low, and 27 participants scored in the middle range of externalizing proneness. The Zung Depression scores ranged from normal to mild and moderate depression. STAI-T scores ranged from normal to mild and moderate trait anxiety. The correlation between the internalizing factor scores and ESI scores $(r(123)=.44, p<.01)$ was similar to the correlation between measures assessing internalizing and externalizing dimensions reported in prior studies (e.g., Krueger, Caspi, Moffitt, \& Silva, 1998).

\subsection{Distribution of target and novel effects}

Multivariate effects from a $2 \times 4$ repeated measures General Linear Model with condition (target, novel) by location (frontal, central, parietal, occipital) revealed main effects of condition (Wilks' $\lambda=.548, F(1,124)=102.44, p<.001, \eta_{p}^{2}=$ .45 ), and location (Wilks' $\lambda=.183, F(3,122)=181.26$, $p<.001, \eta_{p}^{2}=.82$ ), as well as a significant condition by location interaction (Wilks' $\lambda=.408, F(3,122)=59.05, p<.001$, $\eta_{p}^{2}=.59$ ). Follow-up comparisons indicated $\mathrm{P} 3$ amplitude to target stimuli was maximal in parietal regions and significantly greater than frontal $\left(t(124)=19.73, p_{\text {tukey }}<.001\right)$, central $\left(t(124)=5.06, p_{\text {tukey }}<.001\right)$, and occipital $(t(124)=$ $\left.15.04, p_{\text {tukey }}<.001\right)$. P3 amplitude to novel stimuli was also significantly greater in parietal regions compared to frontal $\left(t(124)=18.11, p_{\text {tukey }}<.001\right)$, central $(t(124)=9.54$, $\left.p_{\text {tukey }}<.001\right)$, and occipital $\left(t(124)=6.96, p_{\text {tukey }}<.001\right)$. Because the parietal sites yielded the largest P3 amplitude, subsequent analyses focus on parietal regions for assessing P3 amplitudes to both target and novel stimuli. Frontal effects for novel stimuli will also be reported, as frontal sites are well understood to involve greater engagement of frontal regions for novel stimuli. 
TA B L E 1 Descriptive statistics and correlations for self-report and P3 amplitude measures

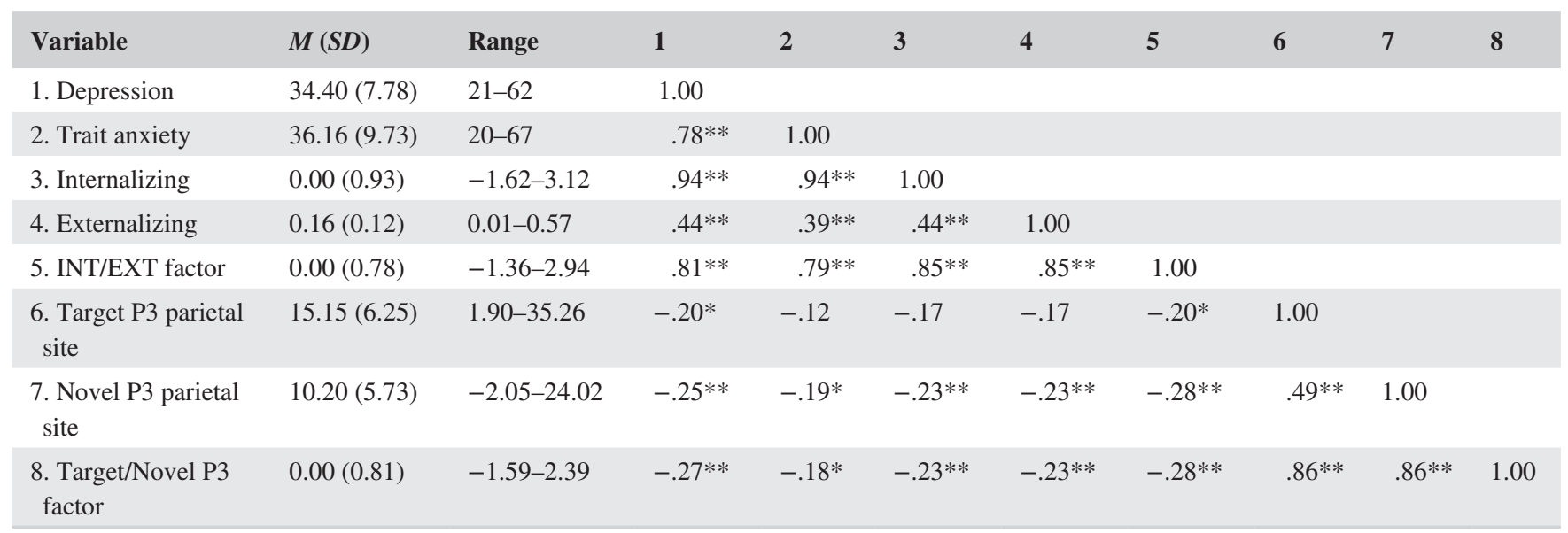

Note: $N=125$ for all measures. INT/EXT are estimated scores of the first factor from a principal axis factor analysis that included the internalizing factor and externalizing scores. Correlation coefficients are Pearson's $r$. $* p<.05 ; * * p<.01$.

\section{3 | Associations between internalizing, externalizing, and $\mathbf{P 3}$ amplitude}

During processing of novel stimuli, parietal P3 was significantly correlated with depression $(r(123)=-.25, p=.004)$, trait anxiety $(r(123)=-.19, p=.036)$, internalizing factor $(r(123)=-.23, p=.009)$, and externalizing $(r(123)=-.23$, $p=.009)$ scores such that greater severity was associated with lower P3 amplitude. Novelty P3 amplitude at the frontal sites also had a significant negative association with trait anxiety scores $(r(123)=-.18, p=.045)$, and a trend for depression $(r=-.15, p=.094)$ and the internalizing factor $(r=$ $-.17, p=.051)$, but not for externalizing $(r=.01, p=.934)$ scores. Figure 2a presents novel stimuli waveforms for the upper and lower quartiles for internalizing and externalizing scores, where P3 amplitude reductions can be observed.

Target stimuli evidenced the same direction of effects as the novel stimuli, but tended to be smaller in magnitude. Target P3 amplitude at the parietal sites had a significant negative association with depression scores $(r(123)=-.20, p=.022)$, but not for trait anxiety $(r(123)=-.12, p=.197)$, internalizing factor $(r(123)=-.17, p=.058)$, or externalizing $(r(123)=-.17, p$ $=.060)$ scores. Although most of the effects did not reach statistical significance, they were all in the direction of greater severity being associated with lower P3 amplitude. Trait anxiety scores did, however, have a significant negative association with target P3 amplitude at frontal sites $(r(123)=-.21, p=$ $.021)$. Figure 3 a presents target stimuli waveforms for the upper and lower quartiles of internalizing and externalizing scores, where $\mathrm{P} 3$ amplitude reductions can be observed.

We also used the target/novel P3 factors scores to assess the associations between scores on the internalizing and externalizing measures and the shared variance across novel and target P3 measures. We observed a consistent and slightly more robust pattern as target/novel P3 factor scores had significant negative associations with depression $(r(123)=-.27, p=$ $.003)$, trait anxiety $(r(123)=-.18, p=.049)$, internalizing factor $(r(123)=-.23, p=.009)$, and externalizing $(r(123)=-.23$, $p=.009)$ scores, such that greater severity was associated with lower scores on the P3 amplitude composite measure.

\subsection{Associations between the INT/EXT Factor and $P 3$ amplitude}

INT/EXT factor scores had significant negative associations with P3 amplitude to novel $(r(123)=-.28, p=.002)$ and target $(r(123)=-.20, p=.026)$ stimuli. This effect is illustrated in Figure $2 b$ and Figure $3 b$ that depict ERP waveforms for the highest and lowest quartiles of the INT/EXT factor scores across frontal, central, parietal, and occipital regions. There was also a significant negative association between the target/novel P3 and INT/EXT factor scores $(r(123)=-.28$, $p=.002)$. Figure 4 shows the corresponding scatterplot depicting this bivariate relationship.

Finally, we fit a series of regression models that included the internalizing factor and externalizing scores as predictors of target P3 amplitude, novelty P3 amplitude, and the novel/ target P3 factor scores, respectively. These models allowed us to test for unique associations between the internalizing and externalizing variables and $\mathrm{P} 3$ amplitude, after adjusting for their shared variance. Results presented in Table 2 indicate that the significant zero-order correlations for the internalizing factor and externalizing scores dropped to a trend-level in the regression model for novel P3 and the target/novel P3 factor scores. However, the multiple $R$ for the regression model was slightly larger than the zero-order correlations, indicating a slight, but $n s$, increase in prediction when the internalizing factor and externalizing scores were entered into the same model. For target $\mathrm{P} 3$, the zero-order correlations were $n s$ nor was the overall 
Novels

(a)

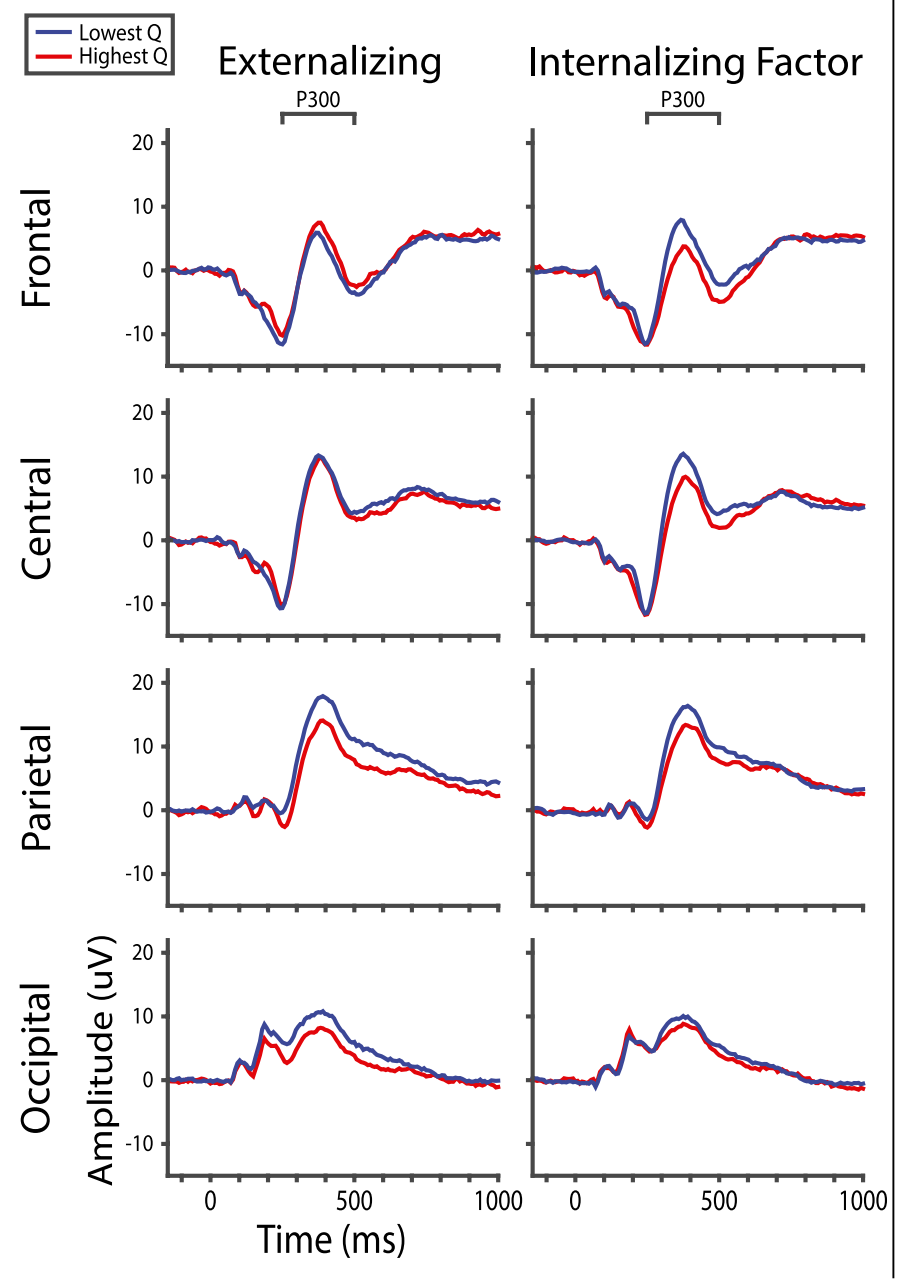

(b)
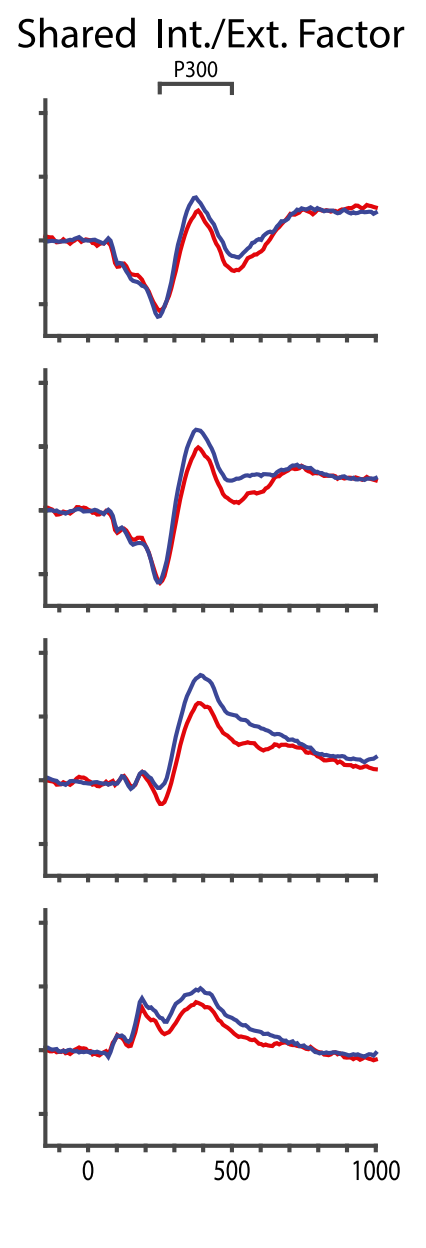

F I G U RE 2 Novels. (a) Average ERP waveforms in frontal, central, parietal, and occipital regions during processing of novel stimuli for highest (red) and lowest (blue) quartiles of externalizing and the internalizing factor scores. P300 amplitude reductions are found for those subjects with the highest externalizing and internalizing factor scores. (b) Average ERP waveforms in frontal, central, parietal, and occipital regions during processing of novel stimuli for highest (red) and lowest (blue) quartiles of the shared internalizing/externalizing factor scores. Quartiles were used here for illustrative purposes only; all analyses were conducted on the full continuous dataset

regression model, though the multiple $R$ was slightly larger than the zero-order correlations, which were all negative. These results suggest that the shared variance between the internalizing factor and externalizing scores accounted for most of their individual associations with measures of P3 amplitude. Also, while there was some evidence for unique associations between internalizing and externalizing scores, the current study lacked sufficient power to detect the smaller residual unique effects.

\section{5 | Assessment of age, gender, and novel picture categories}

Secondary analyses assessed the possibility of other confounding variables including age, gender, and novel picture category on
P3 reduction. Age was not associated with P3 amplitude to target $(r(123)=-.10, p=.256)$ or novel $(r(123)=.00, p=.972)$ stimuli. For gender, independent samples $t$-tests revealed significant differences in P3 amplitude for target stimuli (female $M(S D)=$ 16.1 (6.7) $\mu \mathrm{V}$; male $M(S D)=13.9(5.5) \mu \mathrm{V} ; t(123)=1.99, p$ $=.048$, Cohen's $d=0.36)$ and the novel/target P3 factor scores (female $M(S D)=0.14(0.88)$; male $M(S D)=-0.18(0.68)$, $t(123)=2.20, p=.030$, Cohen's $d=0.41)$, but not for P3 amplitude to novel stimuli (female $M(S D)=11.0(5.9) \mu \mathrm{V}$; male $M$ $(S D)=9.2(5.4) \mu \mathrm{V} ; t(123)=1.78, p=.078$, Cohen's $d=0.32)$. Including gender in a regression model with the INT/EXT factor scores had almost no impact on the beta coefficients of the INT/EXT factor scores, which remained a significant predictor of P3 amplitude to targets $(\beta=-.21, p=.020)$, novels $(\beta=-.28$, $p=.001)$, and target/novel P3 factor scores $(\beta=-.28, p=.001)$. 


\section{$\underline{\text { Targets }}$}

(a)
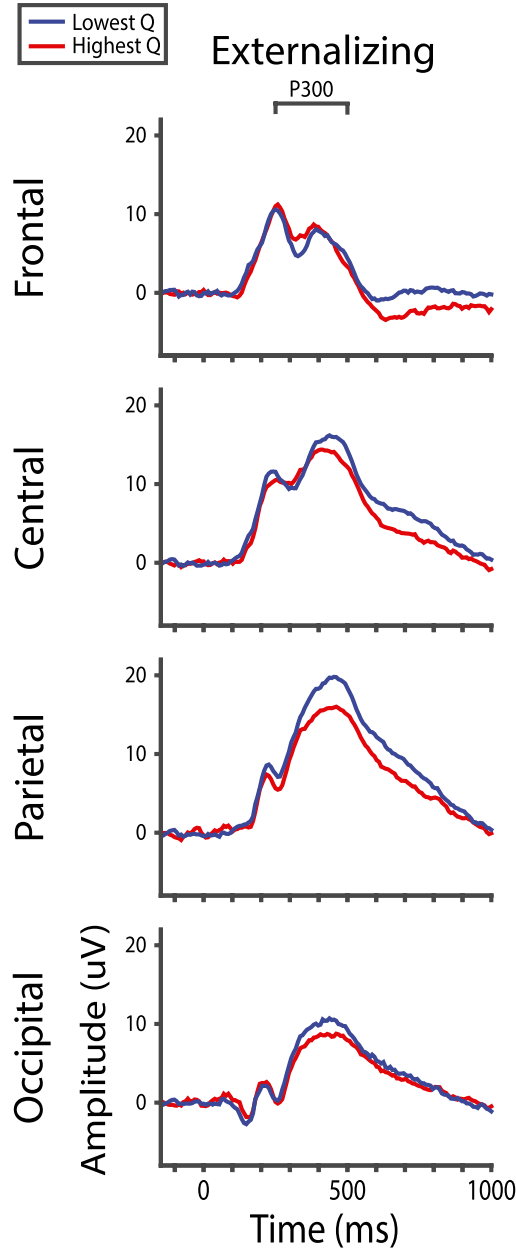

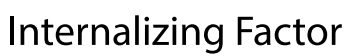
P300
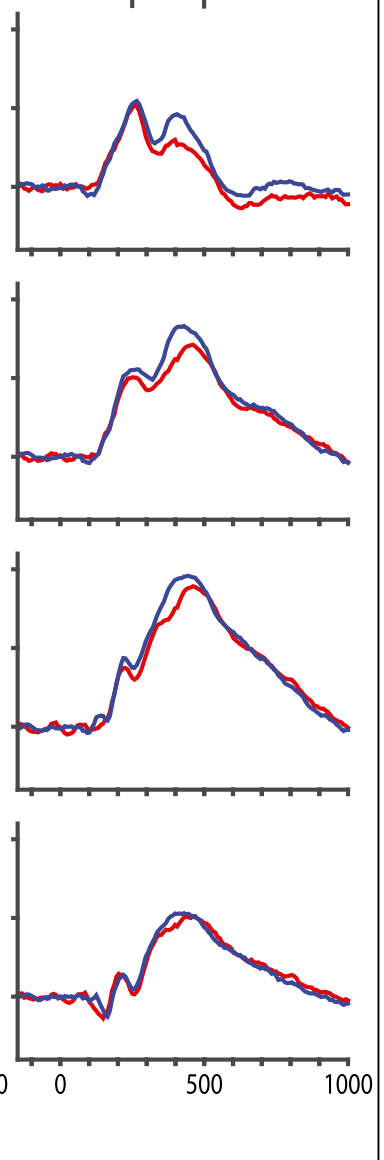

(b)
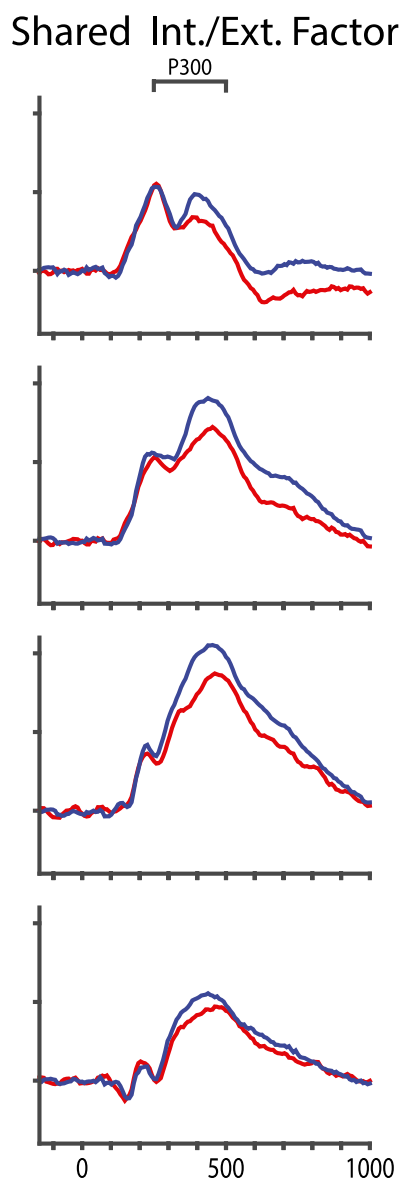

F I G U RE 3 Targets. (a) Average ERP waveforms in frontal, central, parietal, and occipital regions during processing of target stimuli for highest (red) and lowest (blue) quartiles of externalizing and the internalizing factor. P300 amplitude reductions are found for those subjects with the highest externalizing and shared internalizing factor scores. (b) Average ERP waveforms in frontal, central, parietal, and occipital regions during processing of target stimuli for highest (red) and lowest (blue) quartiles of the shared internalizing/externalizing factor scores. Quartiles were used here for illustrative purposes only; all analyses were conducted on the full continuous dataset

To test for affective picture processing differences within the novel stimuli, we examined the associations between P3 amplitudes to each of the three novel picture categories (pleasant, unpleasant, neutral) and their associations with INT/EXT factor scores. Grand average waveforms for these conditions are presented in Figure 5. Figure 5a presents pleasant, unpleasant, and neutral waveforms. Parietal P3 amplitudes to pleasant $(t(124)=4.35, p<.0001)$ and unpleasant $(t(124)=4.59, p<.0001)$ pictures were greater than neutral pictures, consistent with the literature on affective processing effects in ERPs (Cano, Class, \& Polich, 2009; Cuthbert, Schupp, Bradley, Birbaumer, \& Lang, 2000). There were no significant differences between processing pleasant and unpleasant stimuli in parietal regions $(t(124)=0.605, p=.546)$. In frontal regions, however, P3 amplitudes to unpleasant pictures were significantly greater than $\mathrm{P} 3$ amplitudes to pleasant $(t(124)=3.37, p=.001)$ and neutral $(t(124)=4.05$, $p<.001)$ pictures.

Figure $5 \mathrm{~b}$ presents pleasant, unpleasant, and neutral condition waveforms, each split into high and low quartiles of the INT/EXT factor scores. Each show significant correlations with the INT/EXT factor scores such that lower P3 amplitudes correspond to higher factor scores (pleasant: $r(123)=$ $-.21, p=.02$; unpleasant: $r(123)=-.22, p=.01$; neutral: $r(123)=-.24, p=.006)$. Importantly, the magnitude of $\mathrm{P} 3$ reduction between novel picture categories (i.e., pleasantneutral; unpleasant-neutral; pleasant-unpleasant) was not significantly correlated with factor scores (pleasant-neutral: $r(123)=.05, p=.54$; unpleasant-neutral: $r(123)=.03$, $p=.70$; pleasant-unpleasant: $r(123)=.02, p=.81)$. This 
suggests that while picture processing effects were observed, there was no evidence that observed P3 amplitude reductions were differentially related to the affective picture categories.

\section{6 | Assessment of negative affect and substance misuse}

As a post-hoc analysis to test for alternative explanations for the associations between INT/EXT factor scores and P3 amplitude, we tested whether these associations remained after

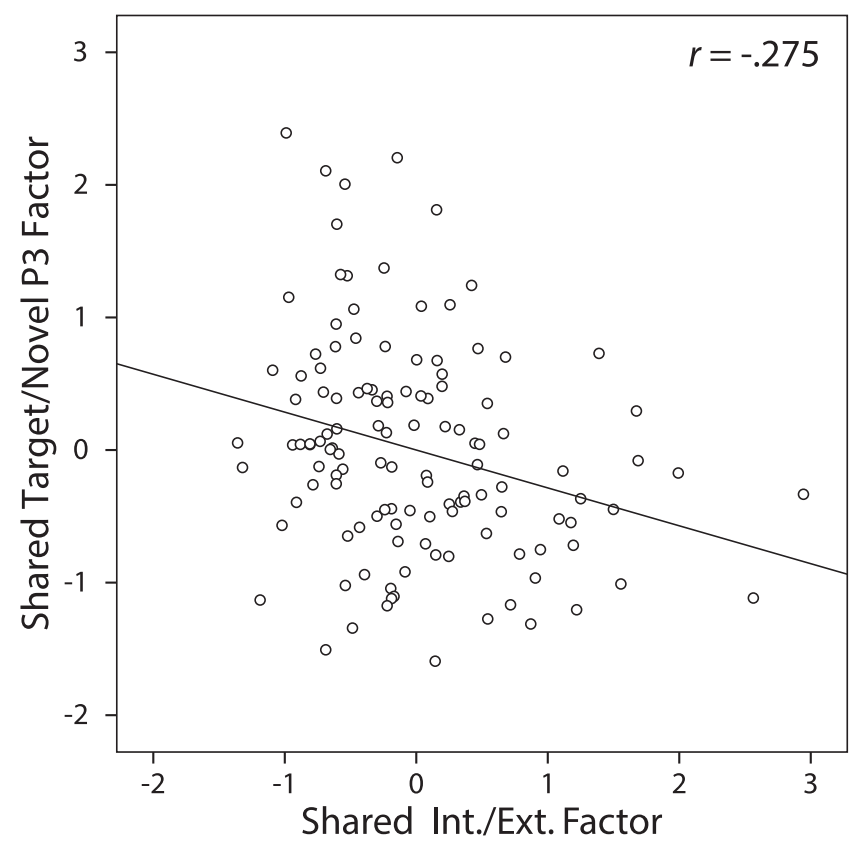

F I G U RE 4 Scatterplot of the association between the shared internalizing/externalizing factor scores and the amplitude of the shared novel/target P300 factor (in microvolts) across all participants $(N=125)$. The solid line represents a best-fitting regression line. As the shared variance across individual difference measures increases, parietal P300 amplitude for the shared novel/target factor decreases accounting for facets of negative emotionality and substance misuse. Negative emotionality has been hypothesized as a candidate factor underlying the $p$-factor or shared variance among internalizing, externalizing, and psychosis-related problems (Lahey et al., 2017; Tackett et al., 2013). Also, substance use and misuse has been widely observed to be related to reduced amplitude of the P3 (Euser et al., 2012). To assess negative emotionality, we used the Negative Emotionality factor from the brief form of the Multidimensional Personality Questionnaire (Patrick, Curtin, \& Tellegen, 2002), and the three affiliated facet scales of stress reaction, alienation, and aggression. For substance use, we use the Alcohol Dependence Scale (Skinner \& Allen, 1982) and the Short Drug Abuse Screening Test (Skinner, 1982).

Table 3 contains the results of the multiple regression models predicting the target/novel P3 amplitude factor scores using the one of the negative emotionality or substance misuse measures and the INT/EXT factor. Only the aggression scale had a significant ( $r=-.27, p=.002$ ) zero-order correlation with target/novel P3 amplitude, and so was the only predictor that diminished the association between the INT/ EXT and target/novel P3 factor scores $(\beta=-.20, p=.036)$ in the regression model. Aggression also remained a significant predictor $(\beta=-.19, p=.040)$ of target/novel P3 factor scores after adjusting for INT/EXT factors scores. While these results indicate that negative emotionality and substance misuse cannot account for the association between INT/EXT and target/novel P3 amplitude factor scores, they do suggest additional content related to aggression may improve the prediction of P3 amplitude measures.

\section{7 $\quad$ Assessment of behavioral data}

To assess any relationship between these effects and behavioral performance in the task, we assessed reaction time and accuracy. Accuracy in the task was high $(M=94 \%$,

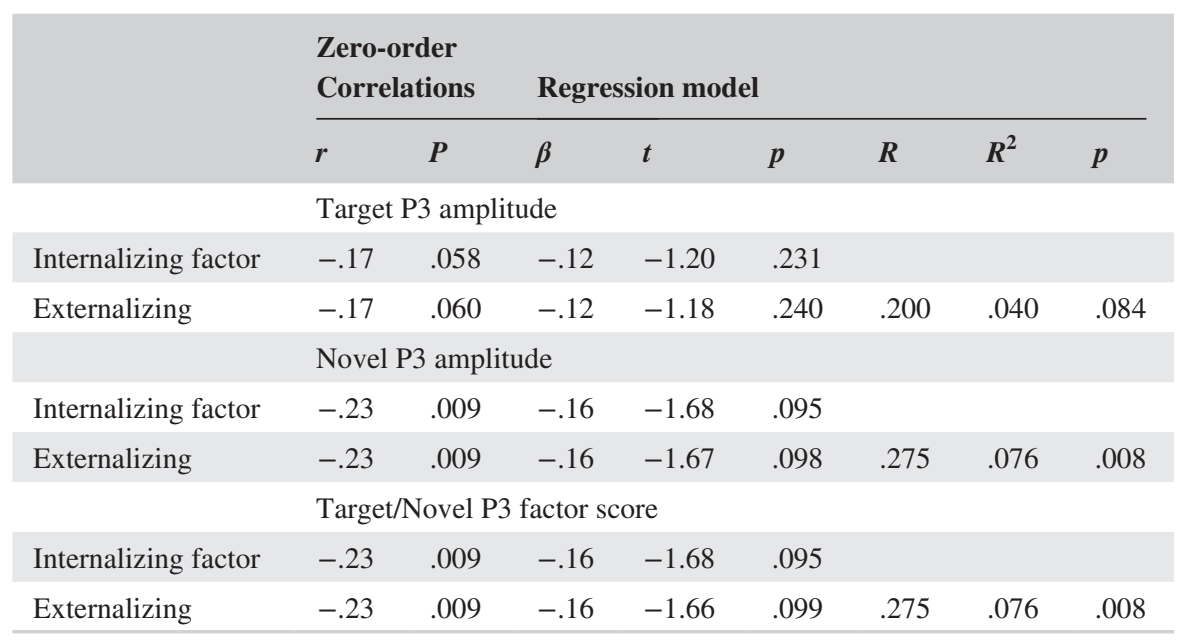

T A B L E 2 Multiple regression results with the shared novel/target P3 amplitude as the criterion, and internalizing (Zung/ STAI-T shared factor) and externalizing problems (ESI, 100 Item) as predictors. Consistent with shared and unique variance for each predictor 
(a)
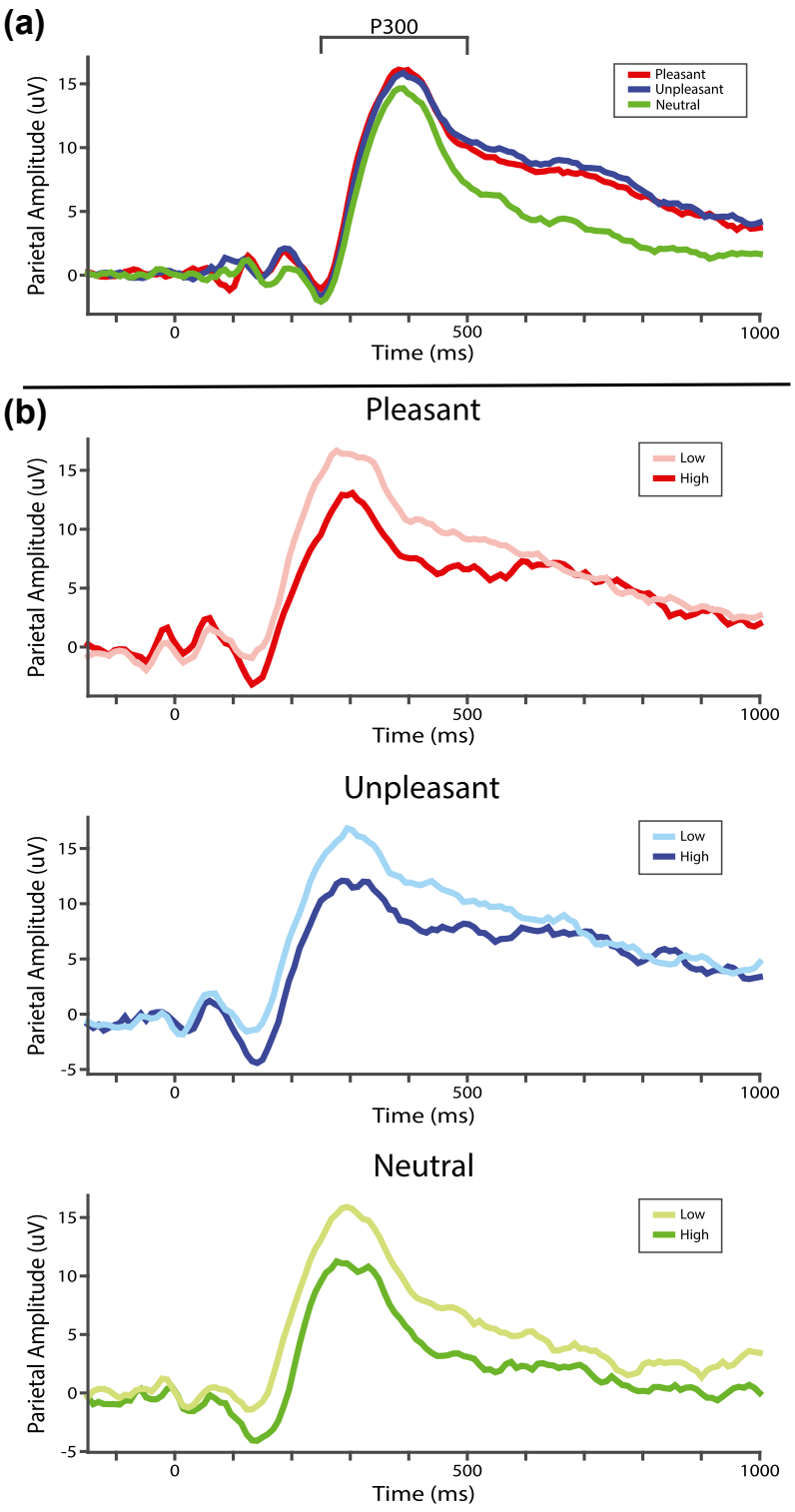

F I G URE 5 (a) Average parietal ERP waveform across all subjects during processing of pleasant (red), unpleasant (blue), and neutral (green) novel stimuli. Pleasant and unpleasant stimuli show significantly greater P300 amplitude compared to neutral. No difference was found between pleasant and unpleasant. (b) Parietal ERP waveforms for pleasant, unpleasant, and neutral and their associations with highest and lowest quartiles of the shared internalizing/externalizing factor scores. Subjects with the highest shared variance factor scores show significantly reduced P300 amplitudes across pleasant, unpleasant, and neutral stimuli $(p<.05)$

median $=97 \%$, mode $=100 \%, S D=9.2 \%$, with expectable reaction time $(\mathrm{RT} ; M=1,049.76$, median $=988.37 \mathrm{~ms}$, mode $583.39 \mathrm{~ms}, S D=272.43$ ), which were log transformed for normality in analysis (several measures of central tendency are given for both accuracy and RT, to more fully describe the distributions). Table 4 presents correlations between the psychopathology measures and the RT and accuracy behavioral measures. RT had significant associations with depression, externalizing, and INT/EXT factor scores, but not with internalizing or anxiety. Accuracy had no significant associations with the psychopathology measures. Next, we examined the associations between the psychopathology measures and target/novel P3 amplitude factor scores after adjusting for RT and accuracy using partial correlations. Associations between the psychopathology measures and target/novel P3 factor scores remained significant after adjusting for RT and accuracy, except for trait anxiety though there was only minor change in the effect size (zero-order $r=-.18$, partial $r^{\prime} s=-.17$ ). These results indicate behavioral performance do not account for the associations between the psychopathology measures and the target/novel P3 amplitude factor scores.

\section{4 | DISCUSSION}

P3 amplitude reductions have been associated with several psychopathology constructs, including those in the externalizing (e.g., substance use, antisocial personality, conduct disorder) and the internalizing domains (e.g., depressive disorders, anxiety disorders). However, there is a lack of research on the degree to which reduced P3 reflects a shared process, relative to the unique effects of specific forms of psychopathology. The current study helps to address this question by assessing P3 amplitude reduction across continuous measures of internalizing and externalizing problems. Consistent with previous findings, we found that lower P3 amplitude was associated with greater severity of internalizing and externalizing problems. We also computed an INT/ EXT factor to measure their shared variance, and found that scores on this factor were significantly associated with reduced P3 amplitude to target and novel stimuli, where relationships tended to be stronger for novels than targets, and a target/novel P3 factor indexing the shared variance across the two P3 measures. These associations were not accounted for by age, gender, novel picture category, or measures of negative emotionality and substance misuse. These results suggest that reduced P3 amplitude may index a common or nonspecific process contributing to both internalizing and externalizing psychopathology.

There has been an increased interest in focusing on the shared variance across externalizing and internalizing dimensions as an important psychopathology construct in recent years. Identifying and examining the correlates of the shared variance across dimensions of psychopathology implies that disorders previously thought to be distinct may have shared mechanisms and neurobiological markers (Lahey et al., 2017). Several factor analytic models have shown that across a broad range of psychiatric disorders, there is evidence for a single factor at the top of the hierarchy, representing the shared variance among the underlying factors 
T A B L E 3 Multiple regression analyses predicting target/novel P3 amplitude factors scores using INT/EXT factor scores and measures of negative emotionality and substance misuse

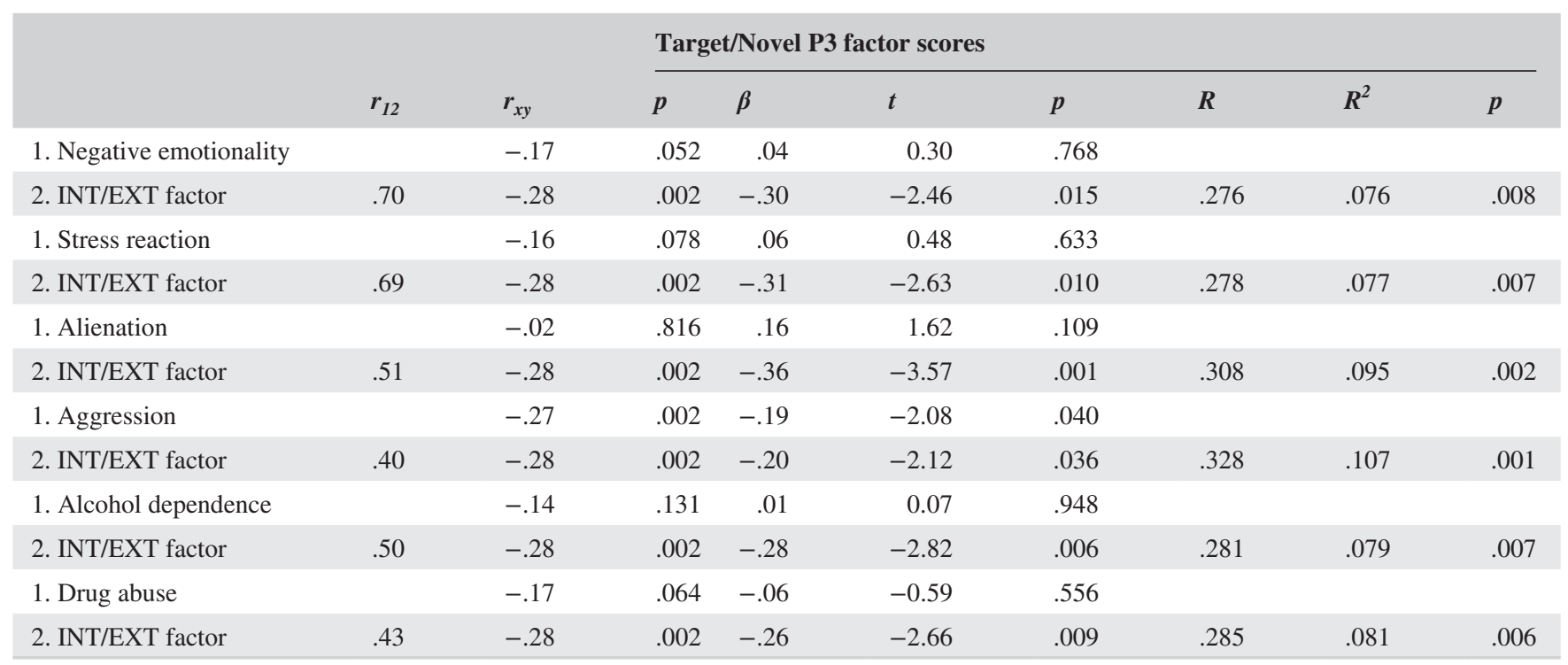

\begin{tabular}{lllll} 
& & & \multicolumn{2}{l}{ Target/Novel P3 factor scores } \\
\cline { 3 - 5 } Variable & $\begin{array}{l}\text { Reaction } \\
\text { time }\end{array}$ & Accuracy & $\begin{array}{l}\text { Partial } \boldsymbol{r} \text { adjusting } \\
\text { for reaction time }\end{array}$ & $\begin{array}{l}\text { Partial } \boldsymbol{r} \\
\text { adjusting for } \\
\text { accuracy }\end{array}$ \\
\hline Depression & $.20 *$ & -.08 & $-.24 * * *$ & $-.26 * * *$ \\
Trait anxiety & .09 & -.08 & $-.17 *$ & $-.17 *$ \\
\hline Internalizing factor & .15 & -.09 & $-.21^{* *}$ & $-.22 * *$ \\
\hline Externalizing & $.21 * *$ & -.03 & $-.20^{* *}$ & $-.23 * * *$ \\
\hline INT/EXT factor & $.22 * *$ & -.07 & $-.24 * * *$ & $-.27 * * *$ \\
\hline
\end{tabular}

T A B L E 4 Correlations between the psychopathology measures and the reaction time (RT) and accuracy behavioral measures

Note: Correlations are reporting Pearson's $r$.

$* p<.10 ; * * p<.05 ; * * * p<.01$.

(Caspi et al., 2014; Lahey et al., 2012, 2017). One theory proposed by this work is that the shared variance across externalizing and internalizing behaviors can be explained by traits reflecting a general factor of psychopathology, labeled "p." This general factor of psychopathology suggests individuals with higher $p$ scores typically have greater life impairments across domains of functioning and possible shared etiologic influences (Caspi et al., 2014). Most importantly, research on the general $p$-factor supports a transdiagnostic approach to the study of psychopathology. Moreover, the general factor of psychopathology may be associated with neurobiological measures that index shared processes across disorders (Lahey et al., 2012, 2015). However, there is a lack of research on neurophysiological markers that may index this shared variance construct. While the shared variance indexed in the current study cannot claim to represent a "p" factor, which is generally defined using diagnostic interview data and structural modeling, it does provide some support for the general idea behind this work that some processes underlying internalizing and externalizing behaviors are shared or related.

Although we could not test causal explanations for the association between P3 amplitude reduction and the nonspecific psychopathology variance, we were able to rule out that this association was due to substance misuse or negative emotionality. Previous literature indicates substance misuse is associated with externalizing and internalizing problems and has also been tied to reduce P3 (for a recent meta-analysis see Euser et al., 2012). However, we found that measures of alcohol dependence and drug abuse failed to account for the association between INT/EXT factor scores and reduced P3 amplitude. Negative affect or emotionality is also common to both internalizing and externalizing problems (Lahey et al., 2017; Mikolajewski, Allan, Hart, Lonigan, \& Taylor, 2013). Negative affect is a pervasive tendency to experience negative or aversive emotions such as anger, sadness, guilt, or nervousness (Watson \& Clark, 1984), and has been shown to partially account for the covariance between 
internalizing and externalizing disorders (Lilienfeld, 2003; Rhee et al., 2007; Tackett et al., 2013). However, we found that neither negative emotionality nor its facets could account for the association between INT/EXT factor scores and reduced P3 amplitude. The aggression facet, however, uniquely predicted P3 amplitude relative to the INT/EXT factor scores, suggesting an important content area worthy of future research.

There are alternative explanations for the association between common psychopathology variance and reduced P3, though these were not within the scope of the current study to test. One such area is trauma history as trauma has been associated with internalizing, externalizing, and reduced P3 amplitudes to both target and novel stimuli (Kimble, Fleming, Bandy, \& Zambetti, 2010). Given these interrelationships, future research should examine whether traumatic experiences may partially account for the association between P3 amplitude reduction and multiple psychopathology constructs. An additional and more complex explanation is based on the etiology of different forms of psychopathology, and suggests that a common genetic component may explain part of the interrelationships across internalizing and externalizing dimensions (Cosgrove et al., 2011; Lahey, Van Hulle, Singh, Waldman, \& Rathouz, 2011). Within different individuals, for example, there could be distinguishable internalizing processes that cause comorbid externalizing, or vice versa, which could account for the observed effects. Given the possibility for additional untested explanations of the effect, future research would benefit from extending the current results through a longitudinal assessment of genetic and environmental (e.g., trauma exposure) mediators between shared externalizing and internalizing behaviors and P3 amplitude modulation.

The topographical distribution of the novelty-P3 reduction effect is also of note, with maximal amplitude reduction over parietal regions. While basic science models have traditionally focused on frontal regions for interpreting novel effects, it has been suggested that processing of novel stimuli incorporates both the frontal and parietal regions through the frontal-parietal attention network and involves different systems with unique functional significance (Friedman, Cycowicz, \& Gaeta, 2001; Knight, 1997; Polich, 2007). Frontally oriented P3 responses to novel stimuli have been shown to reflect processing of unique versus familiar stimuli, with amplitude reduction occurring as a result of habituation to particular types of stimuli (Friedman et al., 2001). However, the parietal P3 component to novel stimuli is proposed as an attention process that is less susceptible to habituation or attenuated response resulting from exogenous task-based factors (Friedman et al., 2001). In relation to psychopathology measures, there is some evidence to suggest novelty-P3 reduction in depressed samples may be most pronounced over the parietal region (Bruder et al., 2012), which is consistent with the current results. We found some evidence of P3 amplitude reduction in frontal regions for novel stimuli related to internalizing (significant for trait anxiety and trend level for depression and INT/EXT factor scores), but not for externalizing, providing weak but suggestive evidence that internalizing problems may be more related to frontal novelty-P3 amplitude reductions than externalizing. Overall, novelty-P3 reduction effects in the current study suggest localization primarily to parietal regions implicated in context updating and emotional stimulus processing. Further study of separable frontal and parietal sources underlying P3 (Bruder et al., 2012; Polich, 2007) could help clarify contributions from different sources to the observed effects.

There are limitations to this study that should be considered when interpreting the findings. One such limitation is the measures indexing externalizing and internalizing constructs. First, both were assessed using self-report measures, which have potential biases and limitations. Second, while the ESI was developed to ensure proper sampling of the externalizing construct, our use of only the Zung Depression scale and STAI-T yielded a somewhat narrow coverage of internalizing-related content. It is also important to note that there is an extensive literature showing that P3 amplitude is reduced with regard to thought disorder (Jeon \& Polich, 2003), and the current study did not recruit for or assess for this. This limits similarity to a " $p$-factor" to internalizing and externalizing problems, excluding thought disorder. Next, this study used a young adult nonclinical sample. Future studies could extend this work to a clinical population for more direct implications related to share variance across psychiatric disorders and P3 stimulus processing. At the same time, the use of continuous rather than categorical measures in this study may provide a better index of the lower levels of problem behaviors in this non-clinical sample. Indeed, recent research has demonstrated the utility of assessing transdiagnostic dimensions rather than categorical disorders (Moser, Moran, \& Jendrusina, 2012; Moser, Moran, Schroder, Donnellan, \& Yeung, 2013; Patrick et al., 2006; Sharp, Miller, \& Heller, 2015). Consistent with the National Institute of Mental Health's Research Domain Criteria (RDoC) initiative, studies investigating transdiagnostic factors have improved our understanding of the neurophysiological processes underlying psychological behaviors (Cuthbert \& Insel, 2013). Finally, it should be noted that while we were sufficiently powered to detect the primary hypothesized relationships, power was lower for detecting smaller effects for anxiety, unique effects of INT and EXT in the regression models, and interactions with gender.

In summary, the current study found support for the idea that reductions in P3 amplitude can reflect, at least in part, a general psychopathology factor. This supports an inference that some biological systems may be sensitive to shared psychological processes (cf. $p$-factor), and further supports the need for more research on biological measures that can index a general factor across individual 
differences. Building upon the current work, future research may strive to better integrate emerging information about the structure of psychopathology into physiological domains where biological systems underlying the structure can be further tested.

\section{CONFLICT OF INTEREST}

None of the authors have potential conflicts of interest to be disclosed.

\section{ORCID}

Jessica S. Ellis iD https://orcid.org/0000-0003-1301-7592

\section{REFERENCES}

Bachman, M. D., \& Bernat, E. M. (2018). Independent contributions of theta and delta time-frequency activity to the visual oddball P3b. International Journal of Psychophysiology, 128, 70-80. https://doi. org/10.1016/j.ijpsycho.2018.03.010

Baribeau-Braun, J., \& Lesèvre, N. (1983). Event-related potential assessment of psychomotor retardation in depressives. Advances in Biological Psychiatry, 13, 211-223. https://doi.org/10.1159/00040 8534

Bauer, L. O., Costa, L., \& Hesselbrock, V. M. (2001). Effects of alcoholism, anxiety and depression on P300 in women: A pilot study. Journal of Studies on Alcohol, 62(5), 571-579. https://doi. org/10.15288/jsa.2001.62.571

Bauer, L. O., \& Hesselbrock, V. M. (1999). Subtypes of family history and conduct disorder: Effects on P300 during the Stroop test. Neuropsychopharmacology, 21(1), 51-62. https://doi.org/10.1016/ S0893-133X(98)00139-0

Begleiter, H., \& Porjesz, B. (1999). What is inherited in the predisposition toward alcoholism? A proposed model. Alcoholism: Clinical and Experimental Research, 23(7), 1125-1135. https://doi. org/10.1111/j.1530-0277.1999.tb04269.x

Begleiter, H., Porjesz, B., Bihari, B., \& Kissin, B. (1984). Event-related brain potentials in boys at risk for alcoholism. Science, 225(4669), 1493-1496. https://doi.org/10.1126/science.6474187

Bernat, E. M., Nelson, L. D., Steele, V. R., Gehring, W. J., \& Patrick, C. J. (2011). Externalizing psychopathology and gain-loss feedback in a simulated gambling task: Dissociable components of brain response revealed by time-frequency analysis. Journal of Abnormal Psychology, 120(2), 352. https://doi.org/10.1037/ a0022124

Blackwood, D. H., Whalley, L. J., Christie, J. E., Blackburn, I. M., St Clair, D. M., \& McInnes, A. (1987). Changes in auditory P3 event-related potential in schizophrenia and depression. The British Journal of Psychiatry, 150(2), 154-160. https://doi.org/10.1192/ bjp.150.2.154

Bruder, G. E., Kayser, J., \& Tenke, C. E. (2012). Event-related brain potentials in depression: Clinical, cognitive and neurophysiologic implications. The Oxford Handbook of Event-Related Potential Components, 2012, 563-592. https://doi.org/10.1093/oxfor $\mathrm{dhb} / 9780195374148.013 .0257$

Cano, M. E., Class, Q. A., \& Polich, J. (2009). Affective valence, stimulus attributes, and P300: Color vs. black/white and norma vs. scrambled images. International Journal of Psychophysiology, 71(1), 17-24. https://doi.org/10.1016/j.ijpsycho.2008.07.016
Caspi, A., Houts, R. M., Belsky, D. W., Goldman-Mellor, S. J., Harrington, H. L., Israel, S., ... Moffitt, T. E. (2014). The p factor: One general psychopathology factor in the structure of psychiatric disorders? Clinical Psychological Science, 2(2), 119-137. https:// doi.org/10.1177/2167702613497473

Comerchero, M. D., \& Polich, J. (1998). P3a, perceptual distinctiveness, and stimulus modality. Cognitive Brain Research, 7(1), 41-48. https://doi.org/10.1016/S0926-6410(98)00009-3

Comerchero, M. D., \& Polich, J. (1999). P3a and P3b from typical auditory and visual stimuli. Clinical Neurophysiology, 110(1), 24-30. https://doi.org/10.1016/S0168-5597(98)00033-1

Cosgrove, V. E., Rhee, S. H., Gelhorn, H. L., Boeldt, D., Corley, R. C., Ehringer, M. A., ... Hewitt, J. K. (2011). Structure and etiology of co-occurring internalizing and externalizing disorders in adolescents. Journal of Abnormal Child Psychology, 39(1), 109-123. https://doi.org/10.1007/s10802-010-9444-8

Cuthbert, B. N., \& Insel, T. R. (2013). Toward the future of psychiatric diagnosis: The seven pillars of RDoC. BMC Medicine, 11(1), 126. https://doi.org/10.1186/1741-7015-11-126

Cuthbert, B. N., Schupp, H. T., Bradley, M. M., Birbaumer, N., \& Lang, P. J. (2000). Brain potentials in affective picture processing: Covariation with autonomic arousal and affective report. Biological Psychology, 52(2), 95-111. https://doi.org/10.1016/ S0301-0511(99)00044-7

Deldin, P. J., Keller, J., Gergen, J. A., \& Miller, G. A. (2001). Cognitive bias and emotion in neuropsychological models of depression. Cognition \& Emotion, 15(6), 787-802. https://doi. org/10.1080/02699930143000248

Demiralp, T., Ademoglu, A., Comerchero, M., \& Polich, J. (2001). Wavelet analysis of P3a and P3b. Brain Topography, 13(4), 251267. https://doi.org/10.1023/A:1011102628306

Dierks, T., Frölich, L., Ihl, R., \& Maurer, K. (1994). Event-related potentials and psychopharmacology. Pharmacopsychiatry, 27(02), 72-74. https://doi.org/10.1055/s-2007-1014282

Diner, B. C., Holcomb, P. J., \& Dykman, R. A. (1985). P300 in major depressive disorder. Psychiatry Research, 15(3), 175-184. https:// doi.org/10.1016/0165-1781(85)90074-5

Enoch, M. A., White, K. V., Harris, C. R., Rohrbaugh, J. W., \& Goldman, D. (2001). Alcohol use disorders and anxiety disorders: Relation to the P300 event-related potential. Alcoholism: Clinical and Experimental Research, 25(9), 1293-1300. https://doi. org/10.1111/j.1530-0277.2001.tb02350.x

Euser, A. S., Arends, L. R., Evans, B. E., Greaves-Lord, K., Huizink, A. C., \& Franken, I. H. (2012). The P300 event-related brain potential as a neurobiological endophenotype for substance use disorders: A meta-analytic investigation. Neuroscience \& Biobehavioral Reviews, 36(1), 572-603. https://doi.org/10.1016/j.neubiorev.2011.09.002

Faul, F., Erdfelder, E., Lang, A. G., \& Buchner, A. (2007). G* Power 3: A flexible statistical power analysis program for the social, behavioral, and biomedical sciences. Behavior Research Methods, 39(2), 175-191. https://doi.org/10.3758/BF03193146

Friedman, D., Cycowicz, Y. M., \& Gaeta, H. (2001). The novelty P3: An event-related brain potential (ERP) sign of the brain's evaluation of novelty. Neuroscience \& Biobehavioral Reviews, 25(4), 355-373. https://doi.org/10.1016/S0149-7634(01)00019-7

Gangadhar, B. N., Ancy, J., Janakiranaiah, N., \& Umapathy, C. (1993). P300 amplitude in non-bipolar, melancholic depression. Journal of Affective Disorders, 28(1), 57-60. https://doi.org/10.1016/01650327(93)90077-W 
Hagen, G. F., Gatherwright, J. R., Lopez, B. A., \& Polich, J. (2006). P3a from visual stimuli: Task difficulty effects. International Journal of Psychophysiology, 59(1), 8-14. https://doi.org/10.1016/j.jpsy cho.2005.08.003

Hall, J. R., Bernat, E. M., \& Patrick, C. J. (2007). Externalizing psychopathology and the error-related negativity. Psychological Science, 18(4), 326-333. https://doi. org/10.1111/j.1467-9280.2007.01899.x

Hansenne, M., Pitchot, W., Moreno, A. G., Zaldua, I. U., \& Ansseau, M. (1996). Suicidal behavior in depressive disorder: An event-related potential study. Biological Psychiatry, 40(2), 116-122. https://doi. org/10.1016/0006-3223(95)00372-X

Hansenne, M., Pitchot, W., Papart, P., \& Ansseau, M. (1998). Serotonergic modulation of the P300 event related brain potential. Human Psychopharmacology: Clinical and Experimental, 13(4), 239-243. https://doi.org/10.1002/(SICI)1099-1077(19980 6)13:4<239:AID-HUP986>3.0.CO;2-V

Hicks, B. M., Bernat, E., Malone, S. M., Iacono, W. G., Patrick, C. J., Krueger, R. F., \& McGue, M. (2007). Genes mediate the association between P3 amplitude and externalizing disorders. Psychophysiology, 44(1), 98-105. https://doi. org/10.1111/j.1469-8986.2006.00471.x

Holguín, S. R., Porjesz, B., Chorlian, D. B., Polich, J., \& Begleiter, H. (1999). Visual P3a in male subjects at high risk for alcoholism. Biological Psychiatry, 46(2), 281-291. https://doi.org/10.1016/ S0006-3223(98)00247-9

Houston, R. J., Bauer, L. O., \& Hesselbrock, V. M. (2003). Depression and familial risk for substance dependence: A P300 study of young women. Psychiatry Research: Neuroimaging, 124(1), 49-62. https:// doi.org/10.1016/S0925-4927(03)00074-X

Iacono, W. G., Malone, S. M., \& McGue, M. (2003). Substance use disorders, externalizing psychopathology, and P300 event-related potential amplitude. International Journal of Psychophysiology, 48(2), 147-178. https://doi.org/10.1016/S0167-8760(03)00052-7

IBM Corp. (2013). IBM SPSS Statistics for Windows, Version 22.0. Armonk, NY: IBM Corp.

Jeon, Y. W., \& Polich, J. (2003). Meta-analysis of P300 and schizophrenia: Patients, paradigms, and practical implications. Psychophysiology, 40(5), 684-701. https://doi.org/10.1111/1469-8986.00070

Johnson, R. Jr. (1993). On the neural generators of the P300 component of the event-related potential. Psychophysiology, 30(1), 90-97. https://doi.org/10.1111/j.1469-8986.1993.tb03208.x

Karaaslan, F., Gonul, A. S., Oguz, A., Erdinc, E., \& Esel, E. (2003). P300 changes in major depressive disorders with and without psychotic features. Journal of Affective Disorders, 73(3), 283-287. https://doi.org/10.1016/S0165-0327(01)00477-3

Katayama, J., \& Polich, J. (1998). Stimulus context determines P3a and P3b. Psychophysiology, 35, 23-33. https://doi. org/10.1111/1469-8986.3510023

Kendler, K. S., Prescott, C. A., Myers, J., \& Neale, M. C. (2003). The structure of genetic and environmental risk factors for common psychiatric and substance use disorders in men and women. Archives of General Psychiatry, 60(9), 929-937. https://doi.org/10.1001/archp syc.60.9.929

Kimble, M. O., Fleming, K., Bandy, C., \& Zambetti, A. (2010). Attention to novel and target stimuli in trauma survivors. Psychiatry Research, 178(3), 501-506. https://doi.org/10.1016/j.psychres.2009.10.009

Kimble, M., Kaloupek, D., Kaufman, M., \& Deldin, P. (2000). Stimulus novelty differentially affects attentional allocation in PTSD.
Biological Psychiatry, 47(10), 880-890. https://doi.org/10.1016/ S0006-3223(99)00258-9

Knight, R. T. (1997). Distributed cortical network for visual attention. Journal of Cognitive Neuroscience, 9(1), 75-91. https://doi. org/10.1162/jocn.1997.9.1.75

Knight, R. T., Scabini, D., Woods, D. L., \& Clayworth, C. C. (1989). Contributions of temporal-parietal junction to the human auditory P3. Brain Research, 502(1), 109-116. https://doi.org/10.1016/00068993(89)90466-6

Krueger, R. F. (1999). The structure of common mental disorders. Archives of General Psychiatry, 56(10), 921-926. https://doi. org/10.1001/archpsyc.56.10.921

Krueger, R. F., Caspi, A., Moffitt, T. E., \& Silva, P. A. (1998). The structure and stability of common mental disorders (DSM-III-R): A longitudinal-epidemiological study. Journal of Abnormal Psychology, 107(2), 216. https://doi.org/10.1037/0021-843X.107.2.216

Krueger, R. F., Hicks, B. M., Patrick, C. J., Carlson, S. R., Iacono, W. G., \& McGue, M. (2002). Etiologic connections among substance dependence, antisocial behavior and personality: Modeling the externalizing spectrum. Journal of Abnormal Psychology, 111(3), 411. https://doi.org/10.1037/0021-843X.111.3.411

Krueger, R. F., \& Markon, K. E. (2006). Reinterpreting comorbidity: A model-based approach to understanding and classifying psychopathology. Annual Review of Clinical Psychology, 2, 111-133. https:// doi.org/10.1146/annurev.clinpsy.2.022305.095213

Krueger, R. F., Markon, K. E., Patrick, C. J., Benning, S. D., \& Kramer, M. D. (2007). Linking antisocial behavior, substance use, and personality: An integrative quantitative model of the adult externalizing spectrum. Journal of Abnormal Psychology, 116(4), 645-666. https://doi.org/10.1037/0021-843X.116.4.645

Lahey, B. B., Applegate, B., Hakes, J. K., Zald, D. H., Hariri, A. R., \& Rathouz, P. J. (2012). Is there a general factor of prevalent psychopathology during adulthood? Journal of Abnormal Psychology, 121(4), 971-977. https://doi.org/10.1037/a0028355

Lahey, B. B., Krueger, R. F., Rathouz, P. J., Waldman, I. D., \& Zald, D. H. (2017). A hierarchical causal taxonomy of psychopathology across the life span. Psychological Bulletin, 143(2), 142-186. https://doi.org/10.1037/bul0000069

Lahey, B. B., Rathouz, P. J., Keenan, K., Stepp, S. D., Loeber, R., \& Hipwell, A. E. (2015). Criterion validity of the general factor of psychopathology in a prospective study of girls. Journal of Child Psychology and Psychiatry, 56(4), 415-422. https://doi.org/10.1111/ jcpp. 12300

Lahey, B. B., Van Hulle, C. A., Singh, A. L., Waldman, I. D., \& Rathouz, P. J. (2011). Higher-order genetic and environmental structure of prevalent forms of child and adolescent psychopathology. Archives of General Psychiatry, 68(2), 181-189. https://doi.org/10.1001/ archgenpsychiatry.2010.192

Lilienfeld, S. O. (2003). Comorbidity between and within childhood externalizing and internalizing disorders: Reflections and directions. Journal of Abnormal Child Psychology, 31(3), 285-291. https://doi. org/10.1023/A:1023229529866

Mikolajewski, A. J., Allan, N. P., Hart, S. A., Lonigan, C. J., \& Taylor, J. (2013). Negative affect shares genetic and environmental influences with symptoms of childhood internalizing and externalizing disorders. Journal of Abnormal Child Psychology, 41(3), 411-423. https://doi.org/10.1007/s10802-012-9681-0

Morault, P. M., Bourgeois, M., Laville, J., Bensch, C., \& Paty, J. (1997). Psychophysiological and clinical value of event-related potentials 
in obsessive-compulsive disorder. Biological Psychiatry, 42(1), 46-56. https://doi.org/10.1016/S0006-3223(96)00228-4

Moser, J. S., Moran, T. P., \& Jendrusina, A. A. (2012). Parsing relationships between dimensions of anxiety and action monitoring brain potentials in female undergraduates. Psychophysiology, 49(1), 3-10. https://doi.org/10.1111/j.1469-8986.2011.01279.x

Moser, J., Moran, T., Schroder, H., Donnellan, B., \& Yeung, N. (2013). On the relationship between anxiety and error monitoring: A meta-analysis and conceptual framework. Frontiers in Human Neuroscience, 7, 466. https://doi.org/10.3389/fnhum.2013.00466

Nan, C., Wang, G., Wang, H., Wang, X., Liu, Z., Xiao, L., ... Wu, S. (2018). The P300 component decreases in a bimodal oddball task in individuals with depression: An event-related potentials study. Clinical Neurophysiology, 129(12), 2525-2533. https://doi. org/10.1016/j.clinph.2018.09.012

Nelson, L. D., Patrick, C. J., \& Bernat, E. M. (2011). Operationalizing proneness to externalizing psychopathology as a multivariate psychophysiological phenotype. Psychophysiology, 48(1), 64-72. https://doi.org/10.1111/j.1469-8986.2010.01047.x

Patrick, C. J., Bernat, E. M., Malone, S. M., Iacono, W. G., Krueger, R. F., \& McGue, M. (2006). P300 amplitude as an indicator of externalizing in adolescent males. Psychophysiology, 43(1), 84-92. https://doi.org/10.1111/j.1469-8986.2006.00376.x

Patrick, C. J., Curtin, J. J., \& Tellegen, A. (2002). Development and validation of a brief form of the Multidimensional Personality Questionnaire. Psychological Assessment, 14(2), 150-163. https:// doi.org/10.1037/1040-3590.14.2.150

Pfefferbaum, A., Wenegrat, B. G., Ford, J. M., Roth, W. T., \& Kopell, B. S. (1984). Clinical application of the P3 component of event-related potentials: II. Dementia, depression and schizophrenia. Electroencephalography \& Clinical Neurophysiology/ Evoked Potentials, 59(2), 104-124. https://doi.org/10.1016/01685597(84)90027-3

Picton, T. W. (1992). The P300 wave of the human event-related potential. Journal of Clinical Neurophysiology, 9(4), 456-479. https:// doi.org/10.1097/00004691-199210000-00002

Polich, J. (2004). Clinical application of the P300 event-related brain potential. Physical Medicine and Rehabilitation Clinics, 15(1), 133161. https://doi.org/10.1016/S1047-9651(03)00109-8

Polich, J. (2007). Updating P300: An integrative theory of P3a and P3b. Clinical Neurophysiology, 118(10), 2128-2148. https://doi. org/10.1016/j.clinph.2007.04.019

Polich, J. (2012). Neuropsychology of P300. In S. J. Luck, \& E. S. Kappenman (Eds.), Oxford library of psychology. The Oxford Handbook of Event-Related Potential Components (pp. 159-188). New York, NY: Oxford University Press. https://doi.org/10.1093/ oxfordhb/9780195374148.013.0089

Polich, J., \& Comerchero, M. D. (2003). P3a from visual stimuli: Typicality, task, and topography. Brain Topography, 15(3), 141152. https://doi.org/10.1023/A:1022637732495

Polich, J., \& Criado, J. R. (2006). Neuropsychology and neuropharmacology of P3a and P3b. International Journal of Psychophysiology, 60(2), 172-185. https://doi.org/10.1016/j.jpsycho.2005.12.012

Polich, J., \& Herbst, K. L. (2000). P300 as a clinical assay: Rationale, evaluation, and findings. International Journal of Psychophysiology, 38(1), 3-19. https://doi.org/10.1016/S0167-8760(00)00127-6

Polich, J., \& Kok, A. (1995). Cognitive and biological determinants of P300: An integrative review. Biological Psychology, 41(2), 103146. https://doi.org/10.1016/0301-0511(95)05130-9
Polich, J., Pollock, V. E., \& Bloom, F. E. (1994). Meta-analysis of P300 amplitude from males at risk for alcoholism. Psychological Bulletin, 115(1), 55-73. https://doi.org/10.1037/0033-2909.115.1.55

Pooviboonsuk, P., Dalton, J. A., Curran, H. V., \& Lader, M. H. (1996). The effects of single doses of lorazepam on event-related potentials and cognitive function. Human Psychopharmacology: Clinical and Experimental, 11(3), 241-252. https://doi. org/10.1002/(SICI)1099-1077(199605)11:3<241:AID-HUP79 $5>3.0 . \mathrm{CO} ; 2-0$

Porjesz, B., Begleiter, H., \& Garozzo, R. (1980). Visual evoked potential correlates of information processing deficits in chronic alcoholics. In H. Begleiter (Eds.), Biological Effects of Alcohol. Advances in Experimental Medicine and Biology (vol. 126). Boston, MA: Springer. https://doi.org/10.1007/978-1-4684-3632-7_46

Rhee, S. H., Cosgrove, V. E., Schmitz, S., Haberstick, B. C., Corley, R. C., \& Hewitt, J. K. (2007). Early childhood temperament and the covariation between internalizing and externalizing behavior in school-aged children. Twin Research and Human Genetics, 10(1), 33-44. https://doi.org/10.1375/twin.10.1.33

Rimpel, J., Olbrich, H. M., Pach, J., Scheer, A., Lodemann, E., \& Markus, G. (1995). Auditory event-related potentials in the course of antidepressant treatment: Latencies. Progress in NeuroPsychopharmacology \& Biological Psychiatry, 19(2), 255-262. https://doi.org/10.1016/0278-5846(95)00006-H

Röschke, J., \& Wagner, P. (2003). A confirmatory study on the mechanisms behind reduced P300 waves in depression. Neuropsychopharmacology, 28(S1), S9-S12. https://doi. org/10.1038/sj.npp.1300139

Semlitsch, H. V., Anderer, P., Schuster, P., \& Presslich, O. (1986). A solution for reliable and valid reduction of ocular artifacts, applied to the P300 ERP. Psychophysiology, 23(6), 695-703. https://doi. org/10.1111/j.1469-8986.1986.tb00696.x

Sharp, P. B., Miller, G. A., \& Heller, W. (2015). Transdiagnostic dimensions of anxiety: Neural mechanisms, executive functions, and new directions. International Journal of Psychophysiology, 98(2), 365-377. https://doi.org/10.1016/j.ijpsycho.2015.07.001

Simons, R. F., Graham, F. K., Miles, M. A., \& Chen, X. (2001). On the relationship of P3a and the Novelty-P3. Biological Psychology, 56(3), 207-218. https://doi.org/10.1016/S0301-0511(01)00078-3

Singh, R., Shukla, R., Dalal, P. K., Sinha, P. K., \& Trivedi, J. K. (2000). P300 event related potential in depression. Indian Journal of Psychiatry, 42(4), 402. https://www.ncbi.nlm.nih.gov/pmc/articles/ PMC2962742/

Skinner, A. (1982). The drug abuse screening test. Addictive Behaviors, 7, 363-371. https://doi.org/10.1016/0306-4603(82)90005-3

Skinner, H. A., \& Allen, B. A. (1982). Alcohol dependence syndrome: Measurement and validation. Journal of Abnormal Psychology, 91, 199-209. https://doi.org/10.1037/0021-843X.91.3.199

Spielberger, C., Gorsuch, R., \& Lushene, R. (1970). STAI manual for the state-trait anxiety inventory. Palo Alto, CA: Consulting Psychologists Press.

Sutton, S., Braren, M., Zubin, J., \& John, E. R. (1965). Evoked-potential correlates of stimulus uncertainty. Science, 150(3700), 1187-1188. https://doi.org/10.1126/science.150.3700.1187

Tackett, J. L., Lahey, B. B., Van Hulle, C., Waldman, I., Krueger, R. F., \& Rathouz, P. J. (2013). Common genetic influences on negative emotionality and a general psychopathology factor in childhood and adolescence. Journal of Abnormal Psychology, 122(4), 1142-1153. https://doi.org/10.1037/a0034151 
Thier, P., Axmann, D., \& Giedke, H. (1986). Slow brain potentials and psychomotor retardation in depression. Electroencephalography \& Clinical Neurophysiology, 63(6), 570-581. https://doi. org/10.1016/0013-4694(86)90144-6

Watson, D., \& Clark, L. A. (1984). Negative affectivity: The disposition to experience aversive emotional states. Psychological Bulletin, 96(3), 465-490. https://doi.org/10.1037/0033-2909.96.3.465

Xu, S., Chai, H., Hu, J., Xu, Y., Chen, W., \& Wang, W. (2014). Passive event-related potentials to a single tone in treatment-resistant depression, generalized anxiety disorder, and borderline personality disorder patients. Journal of Clinical Neurophysiology, 31(5), 488492. https://doi.org/10.1097/WNP.0000000000000091

Yamaguchi, S., \& Knight, R. T. (1991). P300 generation by novel somatosensory stimuli. Electroencephalography and Clinical
Neurophysiology, 78(1), 50-55. https://doi.org/10.1016/00134694(91)90018-Y

Zung, W. W. (1965). A self-rating depression scale. Archives of General Psychiatry, 12(1), 63-70. https://doi.org/10.1001/archp syc. 1965.01720310065008

How to cite this article: Bernat EM, Ellis JS, Bachman MD, Hicks BM. P3 amplitude reductions are associated with shared variance between internalizing and externalizing psychopathology. Psychophysiology. 2020;57:e13618. https://doi. org/10.1111/psyp. 13618 